\title{
Colonialism in Early Education, Care, and Intervention: A Knowledge Synthesis
}

\author{
Kathryn Underwood, Nicole Ineese-Nash, and Arlene Haché
}

\begin{abstract}
Kathryn Underwood is a professor in the School of Early Childhood Studies and the project director for the Inclusive Early Childhood Service System (IECSS) Project at Ryerson University. Her work focuses on equity and disability issues in early childhood studies, as well as in education, care, and intervention social policy and practice. Kathryn's research uses critical disability theory as a starting point for understanding how society responds to and constructs childhood through social institutions.
\end{abstract}

Email: kunderwood@ryerson.ca

Nicole Ineese-Nash is an Indigenous scholar, teacher, and researcher. She holds a master's degree in early childhood studies from Ryerson University and is pursuing doctoral studies in social justice education at the University of Toronto. She was formerly a project coordinator for the IECSS Project, which explores family perspectives of navigating disability support services across Ontario, including in Nicole's home community of Constance Lake First Nation. Nicole's research interests include Indigenous concepts of child development, disability, traditional governance, and family support. She is passionate about supporting social justice initiatives, taking a critical lens to colonial social structures that perpetuate harm for particular peoples in society.

Email: nicole.ineesenash@ryerson.ca

Arlene Haché is a program developer with the Keepers of the Circle and liaison for the Council of Wisdom Keepers for the District of Temiskaming. Ms. Haché founded and was executive director of the not-for-profit Centre for Northern Families for 25 years. The Centre primarily served First Nations, Inuit, and Métis women and their families through a variety of services, including child care, family support, and early intervention programs. As a result of her work and leadership in the North, Ms. Haché was awarded the Order of Canada in 2009 and received the Queen Elizabeth II Diamond Jubilee Medal in 2012. Email: arleneh10@hotmail.com

This knowledge synthesis aims to understand Indigenous experiences of early childhood education, care, family support, intervention, health, and Indigenous services in the context of childhood disability. Each of these institutional contexts has its own underlying professional discourses and worldviews. Knowledge from three sources have been synthesized: (1) interviews with Indigenous families about their experiences of having disabled children, conducted through the Inclusive Early Childhood Service System (IECSS) Project; (2) analysis of the IECSS interviews by the District of Temiskaming Elders Council and Indigenous community partners; and (3) the existing body of literature on disability and Indigenous children. This project was conducted in partnership with a mixed team of Indigenous and settler researchers.

Key words: Indigenous childhoods; childhood disability; early intervention

\section{Early intervention and Indigenous children}

Early intervention (EI) is understood to be an important strategy to ensure optimal development for all children and is largely delivered in health or therapeutic settings. Ample research supports the efficacy of EI strategies, which has resulted in broad advocacy for EI, including through international human rights law (United Nations, 2006). However, the rehabilitation focus of EI, and the embedded medical model, have been critiqued because of the tensions that arise between trying to optimize development and ensuring that children are valued as unique individuals (Underwood, Valeo, \& Wood, 2012). EI includes cognitive, social-emotional, communication, physical, and developmental supports, which are offered to children who are identified as having (or are at risk of having) a disability or developmental delay (McCarty \& Romanow, 2009; Underwood, 2012). EI programs are offered within the home (Dunst, Bruder, \& EspeSherwindt, 2014), educational contexts (Barnett, 2011), healthcare centres (Bagnato et al., 2004), communitybased settings (Hiebert-Murphy, Trute, \& Wright, 2011), and clinical services (Zwaigenbaum et al., 2009). The delivery of EI services is often dependent on diagnostic 
assessments which determine eligibility (Bruder, 2010). Screening procedures for young children have been critiqued for the assumption of a single trajectory of development that may not be consistent across all families and cultures (van Widenfelt et al., 2005).

Indigenous children access various supports in non-Indigenous settings, which have underlying pathological frameworks that are inconsistent with Indigenous worldviews (Chapman, 2012). Research suggests that EI programs operating from a medical model (i.e., those that treat developmental differences as resulting from individual characteristics) are less successful than those incorporating a more holistic view of the various factors involved in childhood development (Gerlach \& Zeidler, 2004; Guralnick, 2011). Institutional intervention for Indigenous children may reproduce colonial practices that can be harmful to children's cultural identities and familial connections (Ball, 2008; Chapman, 2012; Ineese-Nash, Bomberry, Underwood, \& Haché, 2017). Understanding Indigenous perspectives of development and disability is crucial to the provision of culturally appropriate EI services (Ball, 2008; IECSS Project, 2017b), but has yet to be a prominent focus of disability research.

\section{Indigenous childhoods, disability, and colonialism}

Indigenous communities have diverse beliefs and traditions that can support culturally safe EI services for Indigenous populations (Battiste \& Youngblood, 2000; Dei, Hall, \& Rosenberg, 2000). Indigenous communities also share values, such as relationships with each other and with the land (Alfred \& Corntassel, 2005). In many Indigenous communities, children are revered as gifts (Greenwood, 2006). Each child brings unique abilities and strengths to the family and the larger community (Guilfoyle, Saggers, Sims, \& Hutchins, 2010). It is the responsibility of those around the child to nurture and foster each child's gifts as they develop (Best Start Resource Centre, 2010). Indigenous communities value what each individual brings to the collective (Fleer, 2004).

Children's development from an Indigenous perspective goes beyond mastering skills or attaining developmental milestones (Greenwood, 2006). The focus instead is on supporting children's relational identities and experiential learning (Ball \& Pence, 2006; Greenwood \& de Leeuw, 2007). Indigenous children accessing disability supports often spend time in multiple environments that can be culturally dissonant from their communities (Ball, 2008). Few early intervention programs are developed specifically for Indigenous children (DiGiacomo et al., 2013) and the lack of integration between cultural services and disability supports can lead to children having to choose between their Indigenous and disability identities (IECSS Project, 2017a, 2017b).

While statistics on Indigenous identity and disability are not readily available, it is estimated that the rate of childhood disability among Indigenous children is double that of the general population in Canada (Durst, 2006). Culturally inappropriate assessments may be leading to overrepresentation of Indigenous children in special education programs and disability services (Fleet \& Kitson, 2009; Nguyen, 2011). Colonialism continues to create social conditions of poverty, environmental risk, and trauma that also are causes of childhood disability (Czyzewski, 2011; Greenwood, 2005). Further, Indigenous peoples are less likely to seek support from mainstream institutions, such as medical and intervention services, and often report receiving inadequate care within these settings (Allan \& Smylie, 2015; DiGiacomo et al., 2013; Woodgate, 2013). The health and well-being of Indigenous children comes from connection with their land and culture, which is not available in mainstream EI services (Greenwood \& de Leeuw, 2012). 


\section{Method}

\section{Family interviews}

Interviews with families about their experiences of accessing disability support services for their young children are the first data source for our knowledge synthesis. Through the first phase of the Inclusive Early Childhood Service System (IECSS) Project we interviewed 67 families, 21 of whom identified as Anishinabek, Haudenosaunee, or Métis. We met the families once per year over a three-year period (2014-17) across five communities in Ontario (the city of Toronto, city of Hamilton, Wellington County, District of Temiskaming, and Constance Lake First Nation). The IECSS Project is a longitudinal institutional ethnography that aims to understand how the processes and social relations in institutions act on families and children. Through the project we have identified many contrasting views of disability that are embedded in early childhood services. In this knowledge synthesis we are interested in the contrast between institutionally constructed disability discourse and Indigenous views of childhood as an empirical tool for analysis of ongoing colonization of Indigenous childhoods (Ball, 2012; Greenwood, 2006; Tremblay et al., 2013).

\section{Elder and community knowledge}

The IECSS Project was guided by the District of Temiskaming Elders Council from the outset. Additionally, the project team consulted with numerous Indigenous-led community agencies throughout the process. This approach was taken to honour Indigenous ways of analyzing and synthesizing information. These discussions focused on understanding the IECSS findings through the cultural, linguistic, and historic viewpoints of Indigenous peoples. In February of 2017, the Elders Council, along with the IECSS research team, hosted a meeting of Indigenous community partners at Native Child and Family Services in Toronto. This gathering was intended to disseminate the results of the first year of the project data to the community partners and engage in a dialogue regarding the findings, and how these results could impact policy development. Subsequently, policy makers were invited for a brief discussion of the project and ideas about policy implications. This meeting was audio-recorded and transcribed. These discussions, as well as previous community meetings, are considered integral to the understanding of Indigenous early childhood disability and experiences of accessing interventions within these communities. Findings from these meetings and additional consultations with the Elders and community partners were used to develop a video (IECSS Project, 2017a) and a policy brief (IECSS Project, 2017b). These discussions are the second data source integrated into this knowledge synthesis project.

\section{Literature search}

A systematic literature review was conducted to examine the current state of the academic literature on childhood disability in Indigenous communities; it forms the third data source. A search of three databases (Proquest, ERIC, and PubMed) with advanced search capacity was conducted using descriptors of Indigeneity (i.e., Aboriginal, First Nation, Indigenous, Native, and American Indian), disability (i.e., disability, special needs, exceptionality) and age (i.e., early childhood) as search criteria. Next, Indigenous-specific academic journals, community agency websites, and government resources were searched for relevant peer-reviewed and grey literature reports. Resources were included in the synthesis review based on relevance of the age range (from early childhood to middle school) and service systems implicated (EI, disability, and health). We did not restrict the review to particular methods, outcomes, or theoretical positions because we were interested in the overall discourse available, as well as the knowledge base in the academic literature. The process of identifying relevant studies began with screening titles and key words within search results (initial search yielded 3210). Abstracts were then reviewed from articles identified as applicable to the search parameters. Further review of particular articles allowed for the narrowing of 
results to 81 . Figure 1 shows a summary of the literature review data sources.

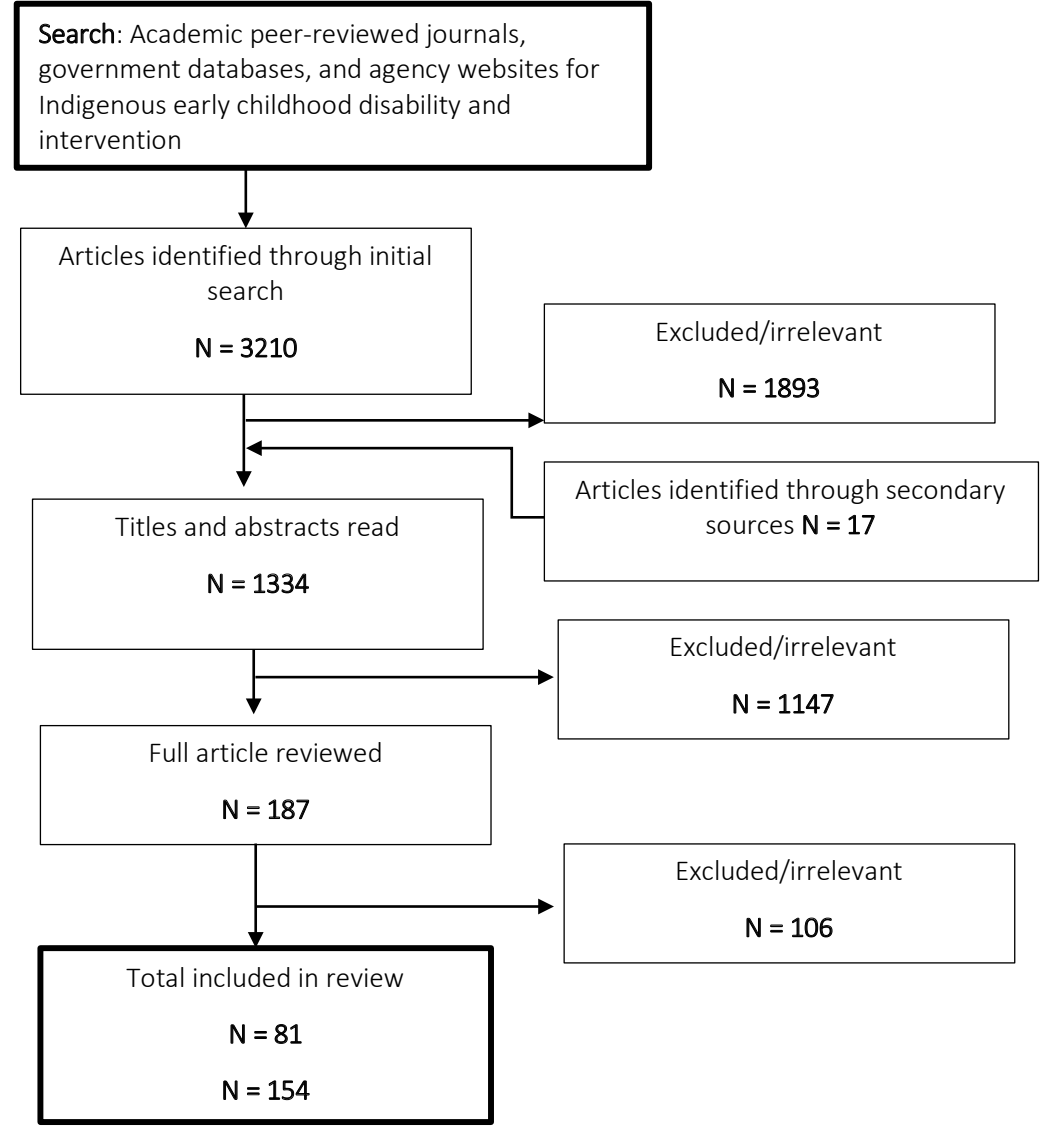

Figure 1. Summary of the literature review process.

\section{Findings}

Our three sources of data yielded similar but variable key concepts, which we describe below.

\section{Family interview findings}

We analyzed the IECSS Project interview data through coding the interviews and mapping families' experiences as they interact with institutional processes. The results indicate that institutional processes in EI, early childhood education and care, and Indigenous services are governed by several factors, including families' worldview and cultural perspectives; historical factors such as family relations and experiences with institutions including residential schools and child apprehension; access to Indigenous services, which includes whether these services are available in a geographic area or if they are offered as part of disability services; geographic accessibility of disability services, particularly on reserve and in the north; the support of families that was evident throughout Indigenous experience; and finally, concerns about transition to school, which were connected to distress about racism, ableism, and understanding of individual characteristics of children by peers and teachers (IECSS Project, 2017a; Ineese-Nash et al., 2007). These findings are described in more detail in the next section as part of the synthesis. 


\section{Elder and community knowledge}

We have identified four areas of focus from the Elders' and community partners' analysis of IECSS findings: cultural-linguistic, access to services, institutional processes, and constructs of disability.

Cultural-linguistic. The Elders and community members identified cultural-linguistic concepts and practices as central to family and childhood experiences. Families spoke about the cultural activities they engage in with their children, such as smudging, attending powwows, and practicing their traditional language. Many families attend a variety of programs in Indigenous-specific agencies with the intention that their child will be able to engage in cultural programming. While parents seek out culturally based early learning and care programs in order for children to have opportunities to learn in cultural ways, these programs are not offered in all communities. Some families expressed feeling connected to their culture when accessing culturally specific programs for their children, even when those programs are not directly focused on teaching parents. A few families engage in ceremonial practices exclusively within service agencies or programs, which gives these environments meaning beyond a support service for the children. The cultural identities of participants in the study are diverse and influence childrearing practices. For example, some participants with some Indigenous heritage identified more closely with their European heritage, which impacted the types of services they would seek for their children.

Families in the study have various perspectives of their children's gifts, which in some cases reflects a cultural viewpoint. Children are described as being unique, special, and at times challenging. Families often describe children's behaviours in the home in ways that differ from the perspectives of service providers. That is to say that certain behaviours or manifestations of disability were not necessarily problematic in the home setting, as families were able to understand the needs of the child and accommodate them. Elders told us that often the disagreements between families and service providers are "cultural misunderstandings" which can lead to the misdiagnosis of children. Cultural expectations vary depending on the environment, which can be difficult for some children to navigate. For instance, one child who was diagnosed with three behavioural conditions by a school psychologist was regarded as a spiritual conduit by his family. Families often have their own explanations for a child's behaviour that are not acknowledged by professionals.

Families also want professional support and some families have strong relationships with service providers. In most cases, however, culture is not an explicit focus of intervention services, which means that children spend time in settings that do not provide cultural teachings. One mother said,

Being a mother and a family person, we try to incorporate our cultural beliefs and spiritual values when raising our children. It is very hard to live in a society where those teachings and values aren't always appreciated. My children have had a very strong understanding since a young age about those cultural values and beliefs. (as cited in Ineese-Nash et al., 2017)

In the current system of services, families are being forced to make decisions between cultural programs and intervention supports. An Elder shared:

[Parents] just don't have time. People do not have time to do both, cultural interactions, cultural learning, and traditional understandings as they raise their children. The priority becomes the physical needs of the child, and that sometimes overtakes that time in a day to be able to come to an office and spend some time learning about drumming and learning about cultural things. (as cited in IECSS Project, 2017a)

Differing cultural perspectives make it difficult for families to access the types of support they feel their child needs while also maintaining traditional and spiritual beliefs. Indigenous partners in the study have told us that many of 
the services that children access are categorized in developmental domains, without a consideration of the spiritual realm. Differences in children's behaviours and displaying of gifts are thought to reflect the child's spirit.

Access to services. Accessing disability support services looks different depending on where a family lives, their unique circumstances, and the perspectives they hold. Families living in northern communities face significantly more challenges in accessing support services than those living in the south. Northern families (such as those living in Temiskaming and Constance Lake) have to travel to access services in urban centres. Professionals coming into northern communities generally serve a large number of families, which limits their capacity to form trusting relationships with children and their families. Elders tell us that to understand children's abilities, we need to look at the values of the family and community, as well as the social conditions in which the child lives.

Perspectives families hold regarding their child, disability, and the service system influence which types of supports they will try to access. Indigenous families often have fewer options, depending on where they live. Some families identified their child as disabled, while others said they felt this is a label put on their child that does not reflect the child's gifts. While these are not mutually exclusive ideas, families who identify with disability are generally more likely to seek institutional supports. Getting disability-specific support, for some families, is the first priority, with particular focus on medical or clinical services, while other families may feel their child benefits more from culturally based programs. Families also may be forced by child protection or social services to engage with service providers.

Institutional processes. Family circumstance plays a crucial role in access to EI services for Indigenous children with disabilities. The manner in which the service system functions puts onus on the family in order for services to be provided to the child. Families' ability to engage in the institutional processes of the service system (such as following up with referrals, filling out paperwork, attending appointments) depends on multiple factors, such as socioeconomic status, literacy levels, health of the parent, knowledge of the service system, and comfort interacting with institutions. This means that some families are able to navigate the service system more easily than others, which can lead to more services for their child. From an institutional ethnography perspective, accessing services is related to families' ability to do the work of the institution, but this ability is largely based on the social position the family holds within that context. In this way, the service system favours particular people, which fosters a social hierarchy and reaffirms colonial structures. One Elder said:

As much as we believe that a specialist can diagnose, who is to say that they as a human being have the responsibility to do so? We as family groups, as family, extended family, aunts, uncles, people that are with our children, those are the people who truly know what it is that this child is capable of and have the ability to succeed in. (as cited in IECSS Project, 2017a)

In addition to physically attending specialist appointments, families also need to follow through with the processes involved with interacting with the service system. Depending on what services are available in a particular region, there may also be additional processes involved with getting travel funding, as families must often travel to urban centres to meet specialists. These obstacles are compounded when a family has more than one family member experiencing disability, or they need to access other services that are not available in their community for multiple family members, which was the case for most families in our study. The more services a family is accessing, the fewer resources a family may have to devote to engaging in institutional processes related to their child's care.

Construction of disability. Indigenous knowledges tell us that children have their own gifts that begin to show as they grow and interact with others around them. Developmental differences are seen by communities as opportunities to learn. In this way, children have gifts to share with others in the community, though it is up to 
those around them to listen and watch to help the child realize these gifts. One cultural advisor explained:

[Children] they know what they need. But sometimes words cannot come out of their mouth. Sometimes doing is the best way they know how and they're showing us physically what needs to be done. [...] We need to give them that ability to be able to walk in a good way in their life and to be able to recognize their gifts that they do have and as an Anishinaabe person, as a gifted person that came into this world to be a good teacher to us. (as cited in IECSS Project, 2017a)

Differences are often seen as strengths within communities. Having said that, many families in the IECSS Project want EI services to support their children in progressing with others their age. Our community partners tell us that differences should be acknowledged and supported while at the same time meeting the child "where they are at." Supporting an individual who may face challenges in participating in community life should be done in a manner that "does less harm" and surrounds the family who are part of the child's life. Diagnoses that are attributed to individual pathology may in fact be caused by trauma related to intergenerational impacts of colonization. Other differences may be a result of a cultural way of raising children that impacts the timing of particular skills, such as the age at which a child walks or talks. Ultimately the mainstream approach that focuses on identifying nonnormative development early, and intervening early, may be in conflict with the Indigenous value of waiting and observing the gifts that a child offers.

\section{Findings from the literature}

Literature on Indigenous early childhood disability is not extensive in comparison to research literature on childhood disability, particularly clinical studies of specific conditions. However, this review identified a body of work that focuses on Indigenous childhood disability in the fields of health, early childhood education and care, and EI services internationally and in Canada. Articles reviewed were predominantly focused on Indigenous populations in Canada (Ball, 2009; Gerlach, 2008), the United States (Ogata, Sheehey, \& Noonan, 2006; Tepper \& Tepper, 2004), New Zealand (Lyons, 2013), and Australia (D’Aprano, Carapetis, \& Andrews, 2011; Nelson \& Allison, 2004). Some Indigenous African (Owusu-Ansah \& Mji, 2013) and South American perspectives (Bailey et al., 1999) were also found. The purpose of this review was to synthesize the existing body of academic and community literature on Indigenous early childhood disability generally; therefore, specific diagnostic categories were not used in the search criteria. We did not restrict the literature review to research specifically by or from Indigenous scholars.

Despite our search criteria, many articles focused on specific categories of impairment such as speech and language support (Peltier, 2017), occupational therapy (Gerlach, 2007), behavioural concerns (Chartonas \& Bose, 2015), autism (Mandell et al., 2009), or educational achievement (Faircloth, 2006). There was also a body of work that included Indigenous experiences of disability in early childhood generally (DiGiacomo et al., 2013) and in special education (Hibel, Faircloth, \& Farkas, 2008), as well as specific discussion of Indigenous early learning (Greenwood, 2006), service navigation (Green et al., 2016), and health (Kenney \& Thierry, 2014). The articles reviewed yielded five broad areas of information: cultural identity and self-determination; pathologizing of Indigenous children and families; environmental and prenatal impacts on development; assessment and diagnosis; and social determinants affecting disability. These are described below with reference to the findings from the IECSS Project and the Elders' and community viewpoints.

Cultural identity and self-determination. The literature suggests that there is an increasing awareness of the role of culture in the development of intervention services and the diagnosis procedures associated with disability support. Limited examples of specific disability support services operating from an Indigenous perspective were identified (Niles, Byers, \& Krueger, 2007 is, however, one example). Many articles spoke about the cultural conceptualization 
of disability and its inherent impact on the provision of EI (e.g., DiGiacomo et al., 2013). Cultural identity is overwhelmingly discussed in the literature as critical to children's development (Greenwood, de Leeuw, \& Fraser, 2007; Joe, 1982; Nichols \& Keltner, 2005), and the development of culturally specific EI programs is seen as a means for Indigenous self-determination (Ball, 2009; Peltier, 2011; Simmons, Novins, \& Allen, 2004). Indigenousled education programs are discussed as a preventative strategy to mitigate negative outcomes associated with particular disabilities and poor social conditions (Greenwood, 2006; Niles et al., 2007; Peltier, 2017; Terbasket \& Greenwood, 2007). Many articles spoke to the impact of colonization on Indigenous health (e.g., Greenwood, de Leeuw, \& Fraser, 2007) and the ability of families to navigate the complex system of services for their children (e.g., Green et al., 2016). Culturally informed disability support may be one way for Indigenous communities to develop intervention systems that allow for Indigenous control of development services (Simmons, Novins, \& Allen, 2004).

Pathologizing of Indigenous children and families. The pathologizing of Indigenous parents and children is found throughout the literature. Studies identify parents as being responsible for their child's disablement (Block, Balcazar, \& Keys, 2001), uninvolved in their development (Hibel et al., 2008), or unequipped to handle the demands of parenting a child with a disability (Joe, 1982). While research supports the claim that Indigenous children are at risk of developmental delays and disability, the underlying assumptions about Indigenous parents as the cause is concerning.

Environmental and prenatal impacts on development. Much of the research on childhood disability in Indigenous communities is focused on drug and alcohol abuse in pregnancy and its impacts on child development (Kenney \& Thierry, 2014) and, to a lesser extent, the impacts of toxic substances from environmental pollutants (Allan \& Smylie, 2015). In addition, a review of research on the prevalence of childhood disability research in Canada indicates an overrepresentation of studies on fetal alcohol syndrome, with little attention to trauma, autism spectrum disorder, and cerebral palsy, leading causes of childhood disability in Canada (Di Pietro \& Illes, 2014). Our research has resisted examining specific disability categories in order to focus on the institutional responses to disability. These institutional practices are often quite generalized, despite the reliance on diagnosis as a gatekeeper. The overall pattern of institutional interaction begins in infancy with hospitals and intensive health care intervention at birth, and then occupational therapies or ongoing health interventions related to specific biological systems of the body, such as the digestive and pulmonary systems. The general pattern of EI is focused on individual pathology, with the added pathologizing of families in a system that automatically links Indigenous women with child protection. Institutional interaction begins with prenatal care, but this creates opportunities for surveillance by social service agencies, which targets Indigenous women. Culture and family support are rarely a significant part of the EI system. While family relations are central to Indigenous child-rearing practices, they are also central to intervention in families where drug and alcohol addiction are present. Also, intervention at the socio-political level is necessary in order to ameliorate the conditions that are the cause of some childhood disability.

Assessment and diagnosis. A number of articles address the difficulty of assessing Indigenous children (Halle, et al. 2011; Niles et al., 2007; Ukrainetz et al., 2000) due to cultural translation (Chartonas \& Bose, 2015), differing perspectives regarding the trajectory of development (Peltier, 2010), and limited interaction with diagnostic professionals in some regions (Aakhus \& Hoover, 1998). Culturally appropriate adaptations of developmental screening tools are largely regarded as a strategy to mitigate cultural conflicts in early childhood assessment and the disproportionate representation of Indigenous children in special education and child welfare (D'Aprano, Carapetis, \& Andrews, 2011; D’Aprano et al., 2016; Morrier \& Gallagher, 2011). Simmons, Novins, and Allen (2004) specifically speak to community-established assessment measures as a model for Indigenous self-determination in the definition of early childhood disability and provision of intervention services. 
Social determinants affecting disability. The literature identifies several social conditions that may affect Indigenous families' interactions with disability and early years services. Overwhelmingly the literature focuses on poverty (Chambers \& Burnett, 2017; Skiba et al., 2005), but to a lesser extent it also discusses racism (Block, Balcazar, \& Keys 2001), education levels (Nichols \& Keltner, 2005), mental health (Kalyanpur, 1998), and social capital (DiGiacomo et al., 2013). The experience of early childhood disability is not only about the child, but also the family and community. The social context in which a child lives has considerable implications for understanding the impact of disability and the necessity for the right type of intervention.

\section{Discussion}

Across the three data sources, culture and language is at the centre of Indigenous understanding. Indigenous cultures are varied and rich, but as a result of long-term colonialism, there is inequitable access to cultural-linguistic resources. All of these data sources describe preservation of culture and language as central to children's resilience. In disability studies, resilience has also been described as a sociocultural phenomenon rather than an individual characteristic (Curran \& Runswick-Cole, 2013).

\section{Self-determination: Indigenous services}

Indigenous communities have been demanding self-determination in all aspects of their lives since the time of the first treaties with European and Canadian governments. The literature review showed a focus on the underlying causes of childhood disability in Indigenous communities, with particular attention to prenatal drug and alcohol exposure and environmental toxins in communities as causes of childhood impairment. The Elders and community members raised very sensitive questions about how Indigenous people are pathologized, and expressed that many Indigenous people have experienced discrimination because of poor understanding in mainstream society about how addiction and environmental toxins are in fact symptoms of colonialism. Our knowledge synthesis suggests that EI and early childhood education, care, and family support initiatives are a critical spot for considering the intersection of childhood disability and Indigenous lives in a respectful way.

\section{Knowledge sharing}

While self-determination is consistent with our most prevalent finding that Indigenous culture and language must be the starting point for any discussion of disability in Indigenous childhoods, we also know that families living in rural and remote communities in particular have a difficult time accessing disability services. We also know that even where services are available, they are not accessible when they are not culturally appropriate and put children and families at risk. Across the three data sources, we found that the organization of services is central to the valuing of Indigenous cultures, but also in the degree to which children with disabilities are accessing early childhood education, care, intervention, and family support. In the larger IECSS study, we have found that many policies that govern general early childhood services make vague references to "inclusion" without explicitly planning for institutions to actually engage in this practice (IECSS Project, 2016a, 2016b). In the sharing of knowledge, it is important not to see Indigenous communities as the recipients of research expertise on disability (as is the case in some of the literature), but as a model of inclusion.

\section{Conclusion}

This knowledge synthesis specifically examines the institutional interactions that families have in the early years. While the knowledge synthesis project and the analysis were conducted by a mixed team of Indigenous and settler researchers, any messages or recommendations should only be implemented in response to the local knowledge of 
specific communities and children. The following key messages were identified through the knowledge synthesis:

1. Indigenous cultural understanding values differences in child development and recognizes children as gifts. Differences in children are part of the gifts that they hold and that make them gifts to their community. Indigenous culture is at the centre of a worldview that values Indigenous childhood and family experience.

2. Social policy that takes Indigenous experiences of childhood disability into account must include Indigenous early childhood education, care, and intervention programs. In order to improve access and inclusion in early childhood education, care, family support, and intervention services, there needs to be better funding for and understanding of Indigenous-specific experiences of childhood disability in both mainstream and Indigenous services.

3. Recognition of the role that institutions play in defining disability as they seek to support optimal development can help to identify theories of disability that are inherent in childhood disability processes and the cultural implications of these processes.

Ongoing research on specific disability experiences should integrate clinical studies with cultural knowledge of Indigenous-specific experiences of childhood disability. While some literature discusses specific childhood disabilities in Indigenous communities, this literature is largely focused on prenatal and environmental causes of disability, with little research on the construct of disability in Indigenous communities and the construct of Indigenous childhoods in mainstream early childhood education, care, family support, and intervention services.

\section{Acknowledgements}

This research was supported by the Social Sciences and Humanities Research Council of Canada Knowledge Synthesis grant \#872-2016-0005. 


\section{References}

Aakhus, B. P., \& Hoover, J. H. (1998). Rural Ojibwe mothers' experiences with early childhood special education services [Research report]. Grand Forks: University of North Dakota Bureau of Educational Services and Applied Research.

Alfred, T., \& Corntassel, J. (2005). Being Indigenous: Resurgences against contemporary colonialism. Government and Opposition, 40(4), 597-614. https://doi.org/10.1111/j.1477-7053.2005.00166.x

Allan, B., \& Smylie, J. (2015). First peoples, second class treatment: The role of racism in the health and well-being of Indigenous peoples in Canada. Toronto, ON: The Wellesley Institute.

Bagnato, S. J., Blair, K., Slater, J., McNally, R., Mathews, J., \& Minzenberg, B. (2004). Developmental healthcare partnerships in inclusive early childhood intervention settings: The HealthyCHILD model. Infants \& Young Children, 17(4), 301-317.

Bailey, D. B., Jr., Skinner, D., Rodriguez, P., Gut, D., \& Correa, V. (1999). Awareness, use, and satisfaction with services for Latino parents of young children with disabilities. Exceptional Children, 65(3), 367-381. https://doi.org/10.1177\%2F001440299906500307

Ball, J. (2008). Aboriginal early language promotion and early intervention. Encyclopedia of language and literacy development (pp. 1-8). London, ON: Canadian Language and Literacy Research Network. Retrieved from http://www.literacyencyclopedia.ca/pdfs/topic. php?topld $=257$

Ball, J. (2009). Aboriginal young children's language development: Promising practices and needs. Canadian Issues, 37, 37-44. Retrieved from http://www.ecdip.org/reports/

Ball, J. (2012). Identity and knowledge in Indigenous young children's experiences in Canada. Childhood Education, 88(5), $286-291$. https://doi.org/10.1080/00094056.2012.717866

Ball, J., \& Pence, A. R. (2006). Supporting Indigenous children's development. Vancouver: UBC Press.

Barnett, W. S. (2011). Effectiveness of early educational intervention. Science, 333(6045), 975-978. https://doi.org/10.1126/ science.1204534

Battiste, M., \& Youngblood, J. (2000). Protecting Indigenous knowledge and heritage: A global challenge. Vancouver: UBC Press.

Best Start Resource Centre. (2010). Founded in culture: Strategies to promote early learning in First Nations children in Ontario. Toronto, ON: Author.

Block, P., Balcazar, F. E., \& Keys, C. B. (2001). From pathology to power: Rethinking race, poverty, and disability. Journal of Disability Policy Studies, 12(1), 18-27. https://doi.org/10.1177\%2F104420730101200103

Bruder, M. B. (2010). Early childhood intervention: A promise to children and families for their future. Exceptional Children, 76(3), 339-355. https://doi.org/10.1177\%2F001440291007600306

Chambers, L., \& Burnett, K. (2017). Jordan’s principle: The struggle to access on-reserve health care for high-needs Indigenous children in Canada. American Indian Quarterly, 41(2), 101-124. https://www.jstor.org/stable/10.5250/amerindiquar.41.issue-2

Chapman, C. (2012). Colonialism, disability, and possible lives: The residential treatment of children whose parents survived Indian residential schools. Journal of Progressive Human Services, 23(2), 127-158. https://doi.org/10.1080/10428232.2012.666727

Chartonas, D., \& Bose, R. (2015). Fighting with spirits: Migration trauma, acculturative stress, and new sibling transition-A clinical case study of an 8-year-old girl with absence epilepsy. Culture, Medicine, and Psychiatry, 39(4), 698-724. https://doi.org/10.1007/ s11013-015-9438-7

Curran, T., \& Runswick-Cole., K. (Eds) (2013). Disabled children's childhood studies: Critical approaches in a global context. Basingstoke, UK: Palgrave Macmillan.

Czyzewski, K. (2011). Colonialism as a broader social determinant of health. The International Indigenous Policy Journal, 2(1/5), 1-14. Retrieved from https://ir.lib.uwo.ca/iipj/vol2/iss1/5/ 
D’Aprano, A. L., Carapetis, J. R., \& Andrews, R. (2011). Trial of a developmental screening tool in remote Australian Aboriginal communities: A cautionary tale. Journal of Paediatrics and Child Health, 47(1-2), 12-17. https://doi.org/10.1111/j.14401754.2010.01883.x

D’Aprano, A. L., Silburn, S., Johnston, V., Robinson, G., Oberklaid, F., \& Squires, J. (2016). Adaptation of the Ages and Stages Questionnaire for remote Aboriginal Australia. Qualitative Health Research, 26(5) 613-625. https://doi.org/10.1177/1049732314562891

Dei, G. J. S., Hall, B., \& Goldin-Rosenberg, D. (Eds.). (2000). Indigenous knowledges in global contexts: Multiple readings of our world. Toronto, ON: University of Toronto Press.

DiGiacomo, M., Davidson, P. M., Abbott, P., Delaney, P., Dharmendra, T., McGrath, S. J. .. \& Vincent, F. (2013). Childhood disability in Aboriginal and Torres Strait Islander peoples: A literature review. International Journal for Equity in Health, 12(1), 7-7. https:// doi.org/10.1186/1475-9276-12-7

Di Pietro N. C., \& Illes, J. (2014). Disparities in Canadian Indigenous health research on neurodevelopmental disorders. Journal of Developmental Behaviour Pediatrics, 35(1), 74-81. https://doi.org/10.1097/DBP.0000000000000002

Dunst, C. J., Bruder, M. B., \& Espe-Sherwindt, M. (2014). Family capacity-building in early childhood intervention: Do context and setting matter? School Community Journal, 24(1), 37-48. Retrieved from https://files.eric.ed.gov/fulltext/EJ1032240.pdf

Durst, D. (2006). Urban Aboriginal families of children with disabilities: Social inclusion or exclusion? National Association of Friendship Centres. Retrieved from https://aboriginalhr.ca/sites/ahrc/files/attachments/Report-NAFC-Disability.pdf

Faircloth, S. C. (2006). Early childhood education among American Indian/Alaskan Native children with disabilities: Implications for research and practice. Rural Special Education Quarterly, 25(1), 25-31. https://doi.org/10.1177\%2F875687050602500105

Fleet, A., \& Kitson, R. (2009). Rethinking assessment in an Indigenous specific program. Alberta Journal of Educational Research, 55(3), 397-413. Retrieved from https://journalhosting.ucalgary.ca/index.php/ajer/article/view/55335/0

Fleer, M. (2004). The cultural construction of family involvement in early childhood education: Some Indigenous Australian perspectives. The Australian Educational Researcher, 31(3), 51-68. Retrieved from https://link.springer.com/article/10.1007/BF03249528

Gerlach, A. (2007). Steps in the right direction: Connecting and collaboration in early intervention in collaboration with Aboriginal families and communities in British Columbia. Vancouver: BC Aboriginal Child Care Society.

Gerlach, A. (2008). "Circle of caring": A First Nations worldview of child rearing. Canadian Journal of Occupational Therapy, 75(1), 18-25. https://doi.org/10.1177\%2F000841740807500107

Gerlach, A., \& Zeidler, D. (2004). A guide for culturally focused early intervention therapy for Aboriginal children and families in British Columbia. BC Aboriginal Child Care Society. Retrieved from https://www.researchgate.net/publication/293334800_A_guide_ for_culturally-focused_early_intervention_therapy_programs_for_Aboriginal_children_and_families_in_British_Columbia

Green, A., Abbott, P., Delaney, P., Patradoon-Ho, P., Delaney, J., Davidson, P. M., \& DiGiacomo, M. (2016). Navigating the journey of Aboriginal childhood disability: A qualitative study of carers' interface with services. BMC Health Services Research, 16(1), 680. Retrieved from https://bmchealthservres.biomedcentral.com/articles/10.1186/s12913-016-1926-0

Greenwood, M. (2005). Children as citizens of First Nations: Linking Indigenous health to early childhood development. Paediatrics \& Child Health, 10(9), 553-555. Retrieved from https://www.ncbi.nlm.nih.gov/pmc/articles/PMC2722642/

Greenwood, M. (2006). Children are a gift to us: Aboriginal-specific early childhood programs and services in Canada. Canadian Journal of Native Education, 29(1), 12-28.

Greenwood, M., \& de Leeuw, S. (2007). Teachings from the land: Indigenous people, our health, our land, and our children. Canadian Journal of Native Education, 30(1), 48-53 Retrieved from https://www.academia.edu/27084290/Teachings_From_the_Land_ Indigenous_People_Our_Health_Our_Land_and_Our_Children

Greenwood, M., \& de Leeuw, S. (2012). Social determinants of health and the future well-being of Aboriginal children in Canada. Paediatrics \& Child Health, 17(7), 381-384. https://doi.org/10.1093/pch/17.7.381 
Greenwood, M., de Leeuw, S., \& Fraser, T. (2007). Aboriginal children and early childhood development and education in Canada: Linking the past and the present to the future. Canadian Journal of Native Education, 30(1), 5-18.

Guilfoyle, A., Saggers, S., Sims, M., \& Hutchins, T. (2010). Culturally strong childcare programs for Indigenous children, families, and communities. Australasian Journal of Early Childhood, 35(3), 68-76. Retrieved from https://ro.ecu.edu.au/ecuworks/6270/

Guralnick, M. J. (2011). Why early intervention works: A systems perspective. Infants and Young Children, 24(1), 6-28. Retrieved from https://www.ncbi.nlm.nih.gov/pmc/articles/PMC3083071/

Halle, T., Zaslow, M., Wessel, J., Moodie, S., \& Darling-Churchill, K. (2011). Understanding and choosing assessments and developmental screeners for young children: Profiles of selected measures. Washington, DC: Office of Planning, Research, and Evaluation, Administration for Children and Families, U.S. Department of Health and Human Services.

Hibel, J., Faircloth, S., \& Farkas, G. (2008). Unpacking the placement of American Indian and Alaska Native students in special education programs and services in the early grades: School readiness as a predictive variable. Harvard Educational Review, 78(3), 498528. https://doi.org/10.17763/haer.78.3.8w010nq4u83348q5

Hiebert-Murphy, D., Trute, B., \& Wright, A. (2011). Parents' definition of effective child disability support services: Implications for implementing family-centered practice. Journal of Family Social Work, 14, 144-158. http://dx.doi.org/10.1080/10522158.2011 552404

IECSS Project. (2016a). Policy Brief No. 4: The Child Care and Early Years Act: Response to proposed regulations and changes to the Child Care and Early Years Act 2014. Retrieved from http://inclusiveearlychildhood.ca/files/2016/03/IECSS_policy-brief_4.pdf

IECSS Project. (2016b). Policy Brief No. 5: Ontario Early Years Child and Family Centres: Opportunity for creation of an inclusive ECEC system. Retrieved from http://iecss.blog.ryerson.ca/files/2014/12/IECSS_policy-brief_5.pdf

IECSS Project. (2017a). IECSS Indigenous findings: Elders video. [K. Underwood and N. Ineese-Nash]. Retrieved from http://iecss.blog. ryerson.ca/library/videos/

IECSS Project. (2017b). Policy Brief No. 7. A submission to the Canadian national engagement on an Indigenous Early Learning and Child Care Framework. Retrieved from http://inclusiveearlychildhood.ca/files/2017/08/IECSS_policy-brief-7_ENG_Jul_-21_2017.pdf

Ineese-Nash, N., Bomberry, Y., Underwood, K., \& Haché, A. (2017) Raising a child with early childhood disability support systems /

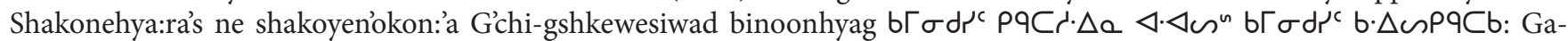
Miinigoowozid Gikendaagoosowin Awaazigish Ga-Miinigoowozid Ga-Izhichigetan. Indigenous Policy Journal, 28(3), 1-14. Retrieved from http://www.indigenouspolicy.org/index.php/ipj/article/view/454

Joe, J. (1982). Cultural influences on Navajo mothers with disabled children. American Indian Quarterly, 6(1/2), 170-190.

Kalyanpur, M. (1998). The challenge of cultural blindness: Implications for family-focused service delivery. Journal of Child and Family Studies, 7, 317-332. Retrieved from https://link.springer.com/article/10.1023/A:1022993512028

Kenney, M. K., \& Thierry, J. (2014). Chronic conditions, functional difficulties, and disease burden among American Indian/Alaska Native children with special health care needs, 2009-2010. Maternal and Child Health Journal, 18(9), 2071-2079. https://doi. org/10.1007/s10995-014-1454-7

Lyons, L. (2013). Transformed understanding or enlightened ableism? The gap between policy and practice for children with disabilities in Aotearoa NewZealand.InternationalJournalofEarly Childhood,45(2),237-249. http://dx.doi.org/10.1007\%2Fs13158-013-0086-1

Mandell, D. S., Wiggins, L. D., Carpenter, L. A., Daniels, J., DiGuiseppi, C., Durkin, M. S., ... \& Shattuck, P. T. (2009). Racial/ethnic disparities in the identification of children with autism spectrum disorders. American Journal of Public Health, 99(3), 493-498. https://doi.org/10.2105/AJPH.2007.131243

McCarty, J., \& Romanow, K. (2009). Navigating the early intervention system. ASHA Leader, 14(4), 1-45. https://doi.org/10.1044/leader. PA1.14042009.1

Morrier, M. J., \& Gallagher, P. A. (2011). Disproportionate representation in placements of preschoolers with disabilities in five southern states. Topics in Early Childhood Special Education, 31(1), 48-57. https://doi.org/10.1177\%2F0271121410363830 
Nelson, A., \& Allison, H. (2004). A visiting occupational therapy service to indigenous children in school: Results of a pilot project. The Australian Journal of Indigenous Education, 33, 55-60. https://doi.org/10.1017/S132601110060087X

Nguyen, M. (2011). Closing the education gap: A case for Aboriginal early childhood education in Canada-A look at the Aboriginal Head Start program. Canadian Journal of Education, 34(3), 229-248. Retrieved from https://www.afn.ca/uploads/files/education2/ closing_the_gap_aboriginal_head_start_2011.pdf

Nichols, L. A., \& Keltner, B. (2005). Indian family adjustment to children with disabilities. American Indian Alaska Native Mental Health Research: The Journal of the National Center, 12(1), 22-48. http://dx.doi.org/10.5820/aian.1201.2005.22

Niles, M., Byers, L., \& Krueger, E. (2007). Best practice and evidence-based research in indigenous early childhood intervention programs. Canadian Journal of Native Education, 30(1), 108-125.

Ogata, V. F., Sheehey, P. H., \& Noonan, M. J. (2006). Rural native Hawaiian perspectives on special education. Rural Special Education Quarterly, 25(1), 7-15. https://doi.org/10.1177\%2F875687050602500103

Owusu-Ansah, F. E., \& Mji, G. (2013). African Indigenous knowledge and research. African Journal of Disability, 2(1), 1-5. Retrieved from https://www.ncbi.nIm.nih.gov/pmc/articles/PMC5442578/

Peltier, S. (2011). Providing culturally sensitive and linguistically appropriate services: An insider construct. Canadian Journal of SpeechLanguage Pathology and Audiology, 35(2), 126-134. Retrieved from https://cjslpa.ca/files/2011_CJSLPA_Vol_35/No_02_103213/Peltier_CJSLPA_2011.pdf

Peltier, S. (2017). An Anishinaabe perspective on children's language learning to inform "seeing the Aboriginal child." Language and Literacy, 19(2), 4-19. https://doi.org/10.20360/G2N95C

Simmons, T. M., Novins, D. K., \& Allen, J. R. (2004). Words have power: (Re)- defining serious emotional disturbance for American Indian and Alaska Native children and their families. American Indian and Alaska Native Mental Health Research: The Journal of the National Center, 11(2), 59-64. Available at: http://www.uchsc.edu/ai/ncaianmhr/journal/11(2).pdf

Skiba, R. J., Poloni-Staudinger, L., Simmons, A. B., Feggins-Azziz, L. R., \& Chung. C. (2005). Unproven links: Can poverty explain ethnic disproportionality in special education? The Journal of Special Education, 39(3), 130-144. https://doi.org/10.1177\% 2F00224669050390030101

Tepper, N., \& Tepper, B. A. (2004). Linking special education with multicultural education for Native American children with special needs. Rural Special Education Quarterly, 23(4), 30-33. https://doi.org/10.1177\%2F875687050402300406

Terbasket, K., \& Greenwood, M. (2007). British Columbia First Nations Head Start program: An overview of policy development 1998 2007. Canadian Journal of Native Education, 30(1), 75-192.

Tremblay, M., Gokiert, R., Georgis, R., Edwards, K., \& Skrypnek, B. (2013). Aboriginal perspectives on social-emotional competence in early childhood. International Indigenous Policy Journal, 4(4). https://doi.org/10.18584/iipj.2013.4.4.2

Ukrainetz, T. A., Cooney, M. H., Dyer, S. K., Kysar, A. J., \& Harris, T. J. (2000). An investigation into teaching phonemic awareness through shared reading and writing. Early Childhood Research Quarterly, 15(3), 331-355. https://psycnet.apa.org/doi/10.1016/ s0885-2006(00)00070-3

Underwood, K. (2012). Mapping the early intervention system in Ontario, Canada. International Journal of Special Education, 27(2), 125-134. Retrieved from https://eric.ed.gov/?id=EJ982867

Underwood, K., Valeo, A., \& Wood, R. (2012). Understanding inclusive early childhood education: A capability approach. Contemporary Issues in Early Childhood, 13(4). https://doi.org/10.2304\%2Fciec.2012.13.4.290

United Nations (2006). UN convention on the rights of persons with disabilities. Retrieved from https://www.un.org/development/desa/ disabilities/convention-on-the-rights-of-persons-with-disabilities.html

van Widenfelt, B. M., Treffers, P. D., De Beurs, E., Siebelink, B. M., \& Koudijs, E. (2005). Translation and cross-cultural adaptation of assessment instruments used in psychological research with children and families. Clinical Child and Family Psychology Review, 8(2), 135-147. https://doi.org/10.1007/s10567-005-4752-1 
Woodgate, R. (2013, June 20). Understanding the disability trajectory of First Nations families of children with disabilities: Advancing Jordan's Principle [brief]. First Nations Families of Children with Disabilities Summit. Retrieved from https://umanitoba.ca/ faculties/nursing/research/media/Booklet_June_Summit.pdf

Zwaigenbaum, L., Bryson, S., Lord, C., Rogers, S., Carter, A., Carver, L., ... \& Fein, D. (2009). Clinical assessment and management of toddlers with suspected autism spectrum disorder: Insights from studies of high-risk infants. Pediatrics, 123(5), 1383-1391. https://doi.org/10.1542/peds.2008-1606 